\title{
Endometrial study by Ultrasonography and its correlation with Histopathology in Abnormal uterine bleeding
}

\author{
Pravin Shrestha, Smita Shrestha, Vibha Mahato \\ Lecturer, Department of Obstetrics and Gynaecology, Manipal College of Medical Sciences, Pokhara, Nepal
}

Background: Abnormal Uterine Bleeding is defined as any deviation from a normal menstrual pattern. It is one of the common presentation in extremes of ages. However endometrial hyperplasia and carcinoma are commoner in perimenopausal and postmenopausal women warranting investigations like ultrasonography and endometrial biopsy. Aims and Objective: The aim of the study was to note the endometrial thickness by transabdominal ultrasonography and observe the histopathological pattern in women presenting with abnormal Uterine Bleeding. Material and Methods: Premenopausal women more than 45 years of age and the postmenopausal patients, without any pelvic pathology were included in the study. Endometrial thickness was measured by transabdominal sonography and endometrial biopsy was done. Tissue obtained was sent for histopathological examination. Results: A total of 105 patients were studied. Majority (92\%) of patients were premenopausal. Proliferative Endometrium (32\%) was the most common finding in premenopausal and atrophic endometrium (37.5\%) in postmenopausal group. Malignancy was higher in a postmenopausal group $(12.5 \%)$ as compared to the premenopausal group (2\%). Malignancy was not seen when endometrial thickness was less than $11 \mathrm{~mm}$ in the premenopausal age group. Endometrial hyperplasia was also more common when the thickness was more than $11 \mathrm{~mm}$.In postmenopausal group $12.5 \%$ of patients, had complex hyperplasia. $25 \%$ had simple hyperplasia and malignancy was seen in $12.5 \%$ of patients. When endometrial thickness was less than $5 \mathrm{~mm}$, hyperplasia and malignancy was not seen. Conclusion: Measurement of Endometrial thickness and histopathological workup in patients above 45 years presenting with abnormal uterine bleeding will be helpful in detecting endometrial hyperplasia and carcinoma.

Access this article online

Website:

http://nepjol.info/index.php/AJMS DOI: 10.3126/ajms.v9i2.19171 E-ISSN: 2091-0576 P-ISSN: 2467-9100

Key words: Abnormal uterine bleeding, Ultrasonography, Endometrial carcinoma

\section{INTRODUCTION}

Abnormal uterine bleeding (AUB) is described as any deviation from a normal menstrual pattern. The key characteristics are regularity frequency, duration of flow, and heaviness of flow, however, each of these parameters may have considerable variability. ${ }^{1 .}$ Bleeding is abnormal when the cycle is irregular, duration of flow is $>7$ days or amount is more than $80 \mathrm{ml}^{2}$ Abnormal uterine bleeding (AUB) is a common presentation responsible for more than $20 \%$ of all visits to outpatient department and for more than $25 \%$ of all hysterectomies. ${ }^{3}$
Evaluation of endometrium by sonography has become an integral component in the investigation of abnormal uterine bleeding since the introduction of ultrasound in gynecological practice by Donald et al in $1958 .{ }^{4}$ Uterine bleeding after permanent cessation of menstruation resulting from loss of ovarian follicular activity is defined as postmenopausal bleeding. Around $3 \%$ of menopausal women suffer from this condition which requires prompt and thorough evaluation. ${ }^{5}$

There is increased risk of endometrial hyperplasia and endometrial carcinoma in premenopausal and 
postmenopausal women with abnormal uterine bleeding. ${ }^{6}$ Therefore, ultrasonography and endometrial biopsy, methods of detecting endometrial hyperplasia or carcinoma must be considered early in investigation.?

An endometrial biopsy is a safe and efficient officebased procedure for sampling the endometrium in a patient presenting with abnormal uterine bleeding. The endometrial tissue obtained provides a diagnosis for wide range of morphologic patterns, normal and abnormal changes like hyperplasia, exogenous hormonal effects, infections, carcinoma which helps in further management. ${ }^{8,9}$

This study was conducted in premenopausal and postmenopausal patients presenting with abnormal uterine bleeding who were subjected to transabdominal sonography. Endometrial biopsy was taken and correlated with the histopathological pattern.

\section{MATERIAL AND METHODS}

This was a prospective study conducted in the Department of Obstetrics and Gynaecology of Manipal Teaching Hospital after approval by the ethical and research committee.

The study population comprised of women aged 45 years and above who attended the gynecological department with complaints of abnormal uterine bleeding. Total of 105 patients was included in the study.

\section{Inclusion criteria}

1. Women aged 45 years and above with abnormal uterine bleeding

2. With no detectable pelvic pathology.

After a detailed history and appropriate clinical examination the patients were subjected to Ultrasonography. Transabdominal Ultrasonography was performed, independent of the phase of menstrual cycle.

Endometrial biopsy was done using Karmann's cannula after signed informed consent and tissue obtained was sent for Histopathological examination. Histopathology reports were divided into seven groups i.e. Proliferative Endometrium, Secretory Endometrium, Simple Hyperplasia, Complex Hyperplasia, Atrophic Endometrium, Endometritis, Malignancy.

Results were compiled. Statistical analysis was done using SPSS 16.

\section{RESULTS}

A total of 105 patients were included in the study. Patients age ranged from 45 to 78 years.

Majority of the patients belonged to the Premenopausal group (92\%) and the rest $8 \%$ were Post-Menopausal.

As shown in Table 1, Proliferative endometrium was the most common finding in Pre-menopausal group (32\%) whereas Atrophic endometrium (37.5\%) in PostMenopausal.

19.5\% of Premenopausal patients had Endometritis.

Malignancy was higher in Post-Menopausal (12.5\%) with respect to Pre-Menopausal (2\%).

According to Table 2, 22\% of patients had endometrial hyperplasia. Simple hyperplasia was

more common (61\%).39\% of patients had Complex hyperplasia. Atypical hyperplasia wasnot noted in our study.

Table 3, shows endometrial thickness in both age groups. $50.5 \%$ of Pre-menopausal patients had endometrial thickness of $11-15 \mathrm{~mm} .50 \%$ postmenopausal had endometrial thickness of $5-10 \mathrm{~mm}$ by ultrasonography.

Table 4, shows a different histopathological pattern with parity. Majority of women were multiparous (87.6\%). Endometrial Hyperplasia was more common in Primipara $(25 \%)$ as compared to multipara (21. 7\%).Endometrial carcinoma was again more in Primipara (8.3\%) as compared to $2.1 \%$ in Multipara

The above Table 5, shows an association of different histopathological pattern with the endometrial thickness

\begin{tabular}{lccc} 
Table 1: Histopathological pattern in pre and post-menopausal age group & \\
Findings & Premenopausal (n=97) & Postmenopausal (n=8) & Total(n=105) \\
\hline Proliferative Endometrium & $31(32 \%)$ & $1(12.5 \%)$ & $32(30.4 \%)$ \\
Secretory Endometrium & $24(25 \%)$ & $0(0 \%)$ & $24(22.8 \%)$ \\
Simple Hyperplasia & $12(12.3 \%)$ & $2(25 \%)$ & $14(13.3 \%)$ \\
Complex Hyperplasia & $8(8.2 \%)$ & $1(12.5 \%)$ & $9(8.5 \%)$ \\
Atrophic Endometrium & $1(1 \%)$ & $3(37.5 \%)$ & $4(3.8 \%)$ \\
Endometritis & $19(19.5 \%)$ & $0(0 \%)$ & $19(18 \%)$ \\
Malignancy & $2(2 \%)$ & $1(12.5 \%)$ & $3(2.8 \%)$ \\
\hline
\end{tabular}


in Premenopausal Group. Malignancy was not seen when endometrial thickness was less than $11 \mathrm{~mm}$.Endometrial Hyperplasia was also more common when the thickness was more than $11 \mathrm{~mm}$.

As shown in Table 6, 12.5\% of patients, had complex hyperplasia.25\% had simple hyperplasia and malignancy was seen in $12.5 \%$ of patients. When endometrial thickness was less than $5 \mathrm{~mm}$, hyperplasia and malignancy was not seen.

\section{DISCUSSION}

Variation in menstrual flow and cycle length are common at extremes of reproductive ages. Endometrial hyperplasia and cancer are more commonly detected in older than in younger age. In Premenopausal women, the likelihood of abnormal endometrial histology is relatively high (14\%) when menses are irregular but very low (less than 1\%) when cycles are regular. ${ }^{10}$ Approximately $10 \%$ (range 1-25\%) of postmenopausal bleeding patients will be diagnosed with endometrial carcinoma. ${ }^{11}$

In the Present study group, the age of the patients ranged from 45 to 78years. A cut off value of 45 years was taken for evaluation of abnormal uterine bleeding and endometrial biopsy. ${ }^{12} 48.5 \%$ of patients had an endometrial

\begin{tabular}{lcc}
\multicolumn{3}{l}{$\begin{array}{l}\text { Table 2: Distribution of cases according to type } \\
\text { of endometrial hyperplasia }\end{array}$} \\
$\begin{array}{lcc}\text { Number of } \\
\text { patients }\end{array}$ & $\begin{array}{c}\text { Number. of } \\
\text { patients (\%) }\end{array}$ \\
\hline Simple Hyperplasia & 14 & 61 \\
Complex Hyperplasia & 9 & 39 \\
Atypical Hyperplasia & 0 & 0 \\
Total & 23 & 100 \\
\hline
\end{tabular}

thickness between 11-15mm on Ultrasonography similar to the study conducted by Dipanshu Sur $(42.3 \%){ }^{13}$

Proliferative endometrium was the most common finding (30.4\%) which indicates anovulatory AUB which occurs in perimenopausal women who is in the follicular phase of an ovarian cycle and proliferative phase of an endometrial cycle. Proliferative endometrium was the predominant finding in $32 \%$ of the premenopausal group and Atrophic endometrium in $37.5 \%$ of the postmenopausal women.

In the study done by Rajshri $\mathrm{P},{ }^{14}$ the predominant histopathological findings were proliferative endometrium $(34.09 \%)$ in perimenopausal women and Atrophic endometrium in the postmenopausal (25.8\%). Similar findings were also noted by Dangal $G^{15}$ where $22 \%$ of patients had endometrial hyperplasia. Simple hyperplasia was more common (61\%).Similar to the study done by Talat Mirza ${ }^{16}$ where $30 \%$ cases were of endometrial hyperplasia. Similar finding was noted by Rajshri P $(23.86 \%)^{14}$ Dangal $(23 \%){ }^{15}$

Malignancy was higher in the postmenopausal (12.5\%) as compared to the premenopausal (2\%).A higher incidence of malignancy was seen in a postmenopausal group in the study done by Dangal G (24.3\% vs $7.7 \%){ }^{15}$ Endometrial hyperplasia was more common inprimipara $(25 \%)$. Endometrial carcinoma was again more in primipara $(8.3 \%)$ as compared to $2.1 \%$ in multipara. As the endometrium is in an inactive state during pregnancy, multipara patients have a lower incidence of endometrial hyperplasia and carcinoma.

In patients, presenting with abnormal uterine bleeding when the endometrial thickness was less than $11 \mathrm{~mm}$ endometrial carcinoma was not observed in Premenopausal

Table 3: Endometrial thickness in different age groups

\begin{tabular}{|c|c|c|c|c|c|c|}
\hline \multirow[t]{2}{*}{ Age group } & \multicolumn{6}{|c|}{ Endometrial thickness } \\
\hline & $<5 \mathrm{~mm}$ & $5-10 \mathrm{~mm}$ & $11-15 \mathrm{~mm}$ & $16-20 \mathrm{~mm}$ & $>20 \mathrm{~mm}$ & Total No. \\
\hline Pre-menopausal & $1(1.03 \%)$ & $33(34.02 \%)$ & $49(50.5 \%)$ & $11(11.3 \%)$ & $3(3.09 \%)$ & 97 \\
\hline
\end{tabular}

Table 4: Correlation of parity with histopathology

\begin{tabular}{|c|c|c|c|}
\hline Findings & Nullipara & Primipara & Multipara \\
\hline Proliferative & 1 & 3 & 28 \\
\hline Secretory & 0 & 2 & 22 \\
\hline Simple Hyperplasia & 0 & 0 & 14 \\
\hline Complex Hyperplasia & 0 & 3 & 6 \\
\hline Atrophic & 0 & 1 & 3 \\
\hline Endometritis & 0 & 2 & 17 \\
\hline Malignancy & 0 & 1 & 2 \\
\hline
\end{tabular}




\begin{tabular}{|c|c|c|c|c|c|c|c|}
\hline \multirow[t]{2}{*}{ HPE } & ET (mm) & $<5$ & $5-10$ & $11-15$ & $16-20$ & $>20$ & Total \\
\hline & \multicolumn{7}{|l|}{ No. of pts } \\
\hline \multicolumn{2}{|c|}{ Proliferative Endometrium } & 1 & 7 & 22 & 1 & 0 & 31 \\
\hline \multicolumn{2}{|c|}{ Secretory Endometrium } & 0 & 13 & 9 & 1 & 1 & 24 \\
\hline \multicolumn{2}{|c|}{ Simple hyperplasia } & 0 & 1 & 8 & 2 & 1 & 12 \\
\hline \multicolumn{2}{|c|}{ Complex Hyperplasia } & 0 & 0 & 1 & 6 & 1 & 8 \\
\hline \multicolumn{2}{|c|}{ Atrophic endometrium } & 0 & 1 & 0 & 0 & 0 & 1 \\
\hline \multicolumn{2}{|c|}{ Endometritis } & 0 & 11 & 8 & 0 & 0 & 19 \\
\hline \multicolumn{2}{|c|}{ Malignancy } & 0 & 0 & 1 & 1 & 0 & 2 \\
\hline \multicolumn{2}{|c|}{ Total } & 1 & 33 & 49 & 11 & 3 & 97 \\
\hline
\end{tabular}

\begin{tabular}{|c|c|c|c|c|c|c|}
\hline \multirow[t]{2}{*}{ Findings } & \multicolumn{6}{|c|}{ Endometrial thickness $(\mathrm{mm})$} \\
\hline & $<5$ & $5-10$ & $11-15$ & $16-20$ & $>20$ & Total \\
\hline Proliferative & 1 & 0 & 0 & 0 & 0 & 1 \\
\hline Secretory & 0 & 0 & 0 & 0 & 0 & 0 \\
\hline $\begin{array}{l}\text { Simple } \\
\text { hyperplasia }\end{array}$ & 0 & 0 & 2 & 0 & 0 & 2 \\
\hline $\begin{array}{l}\text { Complex } \\
\text { hyperplasia }\end{array}$ & 0 & 1 & 0 & 0 & 0 & 1 \\
\hline Atrophic & 0 & 3 & 0 & 0 & 0 & 3 \\
\hline Endometritis & 0 & 0 & 0 & 0 & 0 & 0 \\
\hline Malignancy & 0 & 0 & 0 & 1 & 0 & 1 \\
\hline
\end{tabular}

patients. Morepatients had endometrial hyperplasia when the endometrial thickness was more than $11 \mathrm{~mm}$. Similarly, in the study done by Pilai, complex hyperplasia and malignancy were not noted when the endometrial thickness was less than $14.9 \mathrm{~mm} .{ }^{17}$

In Post-Menopausal patients $37.5 \%$ of patients, had endometrial hyperplasia when the endometrial thickness was more than $5 \mathrm{~mm}$. Endometrial carcinoma was not observed when the endometrial thickness was less than $15 \mathrm{~mm}$.In the study done by Chaudhary $\mathrm{L}^{18}$ mean endometrial thickness in endometrial carcinoma was $11.95 \mathrm{~mm}$.

A cut off point of endometrial thickness for predicting endometrial carcinoma could not be made in our study because of inclusion of both premenopausal and postmenopausal group.

\section{CONCLUSION}

Measurement of endometrial thickness by Ultrasonography and endometrial biopsy in Perimenopausal and postmenopausal women with abnormal bleeding can be a useful tool to identify endometrial hyperplasia and endometrial carcinoma.

\section{REFERENCES}

1. Fraser IS, Critchley HOD, Broder M and Munro MG. The FIGO Recommendation on Terminology and definition for Normal and Abnormal Uterine Bleeding. Seminars in Reproductive Medicine 2011; 29(5):383-390.

2. Speroff $L$ and Fritz MA. Menopause and the peri-menopausal transition in clinical gynaecologic endocrinology and infertility. $7^{\text {th }}$ ed: Jaypee Brothers Med Publishers (P) Ltd, 2005, pp 621-88.

3. Nazim F, Hayat Z, Hannan A, Ikram U and Nazim K. Role of transvaginal ultrasound in identifying endometrial hyperplasia. Journal of Ayub Medical College Abbottabad. 2013; 25(1-2):100-102.

4. Donald I, Macvicar $\mathrm{J}$ and Brown TG. Investigation of abdominal masses by pulsed ultrasound. The Lancet 1958; 271(7032):1188-1195.

5. Singh P, Dwivedi P and Mendiratta S. Correlation of Endometrial Thickness with the Histopathological Pattern of Endometrium in Postmenopausal Bleeding. The Journal of Obstetrics and Gynecology of India 2016; 66(1):42-46.

6. Kumar A and Mittal S. Endometrial sampling: How \& why. Obstetrics and Gynecology Today 2007; 12(6):284-287.

7. Shobhitha GL, Kumari VI, Priya PL and Sundari BT. Endometrial study by TVS and It's correlation with histopathology in abnormal uterine bleeding. J Dental Med Sci 2015;14(4):21-32.

8. Svirsky R, Smorgick N, Rozowski U, Sagiv R, Feingold M, Halperin R, et al. Can we rely on blind endometrial biopsy for detection of focal intrauterine pathology? American Journal of Obstetrics \& Gynecology 2008;199 (2):115.

9. Parmar $J$ and Desai D. Study of endometrial pathology in abnormal uterine bleeding. International Journal of Reproduction, Contraception, Obstetrics and Gynecology. 2016; 2(2):182-185.

10. Ash SJ, Farrell SA and Flowerdew G. Endometrial biopsy in DUB. The Journal of reproductive medicine 1996; 41(12):892-896.

11. Gambrell RD, Castaneda TA and Ricci CA. Management of postmenopausal bleeding to prevent endometrial cancer. Maturitas 1978;1(2):99-106.

12. Pennant ME, Mehta R, Moody P, Hackett G, Prentice A, Sharp SJ, et al. Premenopausal abnormal uterine bleeding and risk of endometrial cancer. BJOG: An International Journal of Obstetrics \& Gynaecology 2017; 124(3):404-411.

13. Sur $D$ and Chakravorty R. Correlation of Endometrial Thickness and Histopathology in women with Abnormal Uterine Bleeding. Reproductive System and Sexual Disorder 2016; 5(4):1-3.

14. Damle RP, Dravid NV, Suryawanshi KH, Gadre AS, Bagale PS and Ahire N. Clinicopathological spectrum of endometrial changes in peri-menopausal and post-menopausal abnormal uterine bleeding: A 2 years study. Journal of clinical and 
diagnostic research 2013;7(12):2774-2776.

15. Dangal G. A study of endometrium of patients with abnormal uterine bleeding at Chitwan valley. Kathmandu University Medical Journal 2003;1(2):110-112.

16. Mirza T, Akram S, Mirza A, Aziz S, Mirza T and Mustansar T. Histopathological pattern of abnormal uterine bleeding in endometrial biopsies. Journal of Basic Applied Science 2012;8(1):114-117.

17. Pillai SS. Sonographic and histopathological correlation and evaluation of endometrium in perimenopausal women with abnormal uterine bleeding. International Journal of Reproduction, Contraception, Obstetrics and Gynecology 2016; 24;3(1):113-117.

18. Chaudhari L and Satia NM. To study the correlation between endometrial thickness on transvaginal sonography and endometrial histopathology in women with postmenopausal bleeding. International Journal Reproduction Contraception Obstetetrics and Gynecology 2016;5(5):1309-1315.

\section{Authors Contribution:}

PS- Concept and design of the study, reviewed the literature, statistically analysed and interpreted, manuscript preparation, critical revision of the manuscript; SS - Collected data and helped in preparing first draft of manuscript; VM- Literature search and helped in critical revision of manuscript.

Orcid ID:

Dr. Smita Shrestha - (1) http://orcid.org/0000-0001-6178-6594

Dr Vibha Mahato - (i) http://orcid.org/0000-0002-5116-0405 